\title{
Organic food consumption in China: the moderating role of inertia
}

\author{
Tsai-Fa Yen ${ }^{\text {a }}$ \\ School of Economics, Sichuan University of Science and Engineering, China
}

\begin{abstract}
Despite the progressive development of the organic food sector across Taiwan Strait, little is known about how consumers' self congruity will influence organic food decision through various degrees of attitude and whether or not consumers with various degrees of inertia will vary in their intention to buy organic foods. The current study aims to examine the effect of consumption self congruity on behavioral intention related to organic food consumption under the mediating role of attitude as well as the moderating role of inertia. Research data were collected from organic food consumers across Taiwan Strait via a questionnaire survey, eventually obtaining 500 valid questionnaires for analysis. This study tested the overall model fit and hypotheses through structural equation modeling method (SEM). The results show that consumer attitude significantly mediates the effects of self congruity on organic food purchase intention. Moreover, the moderating effect of inertia is statistical significance, indicating that the relationship between attitude and purchase intention becomes weaker in the condition of consumers with higher degree of inertia. Several implications and suggestions are also discussed for organic food providers and marketers.
\end{abstract}

\section{Introduction}

In the past two decades, organic food has developed impressively, from a neglected niche market to the food market mainstream [1]. More and more researchers and practitioners are attracted and involved. As [2] ascertained from several studies, the attitude of consumers towards organic food is in general positive with typically associated benefits being superior taste, more environmentalfriendliness, improved health, safer food, and more animal welfare. The foci of prior research into organic foods consumption included identifying motivations behind their purchase to understand the "whys" of consumers' choices. The key drivers previously identified include health benefits and environmental concerns (e.g., [3, 4]), as safety concerns regarding conventional foods (e.g., [3,5]), as well psychological motives (e.g., [6]).

However, despite the valuable insights provided by previous studies, at least two research gaps exist, which must be addressed. That is, previous studies have neglected psychological motives (i.e., self-congruity) and an important role of organic foods, gender. In particular, initial psychological motives, such as self-congruity, deserve attention given their impact on consumers' product choices. Consumers purchase goods/services because they are driven by a motivation to express their own selfimages [7-9]. These self-images to a product or brand was defined, sustained, and enhanced by

\footnotetext{
${ }^{a}$ Corresponding author : 1722997311r@qq.com
}

(C) The Authors, published by EDP Sciences. This is an open access article distributed under the terms of the Creative Commons Attribution License 4.0 (http://creativecommons.org/licenses/by/4.0/). 
consumers. When the images of a product or brand have matched their own self-images, the congruence as known self-congruity was met and they are more likely to be selected and purchased [10]. Consequently, the possibility of psychological motives (i.e., self-congruity) might play an important role in organic product consumption.

Moreover, attitude toward a product/brand has been viewed as an antecedent of behavioral intention and evidence from leisure farming has illustrated it could impact behavioral intention of a consumer $[9,11,12]$. Clarifying its impacts on behavioral intention in the context of organic foods would extend the knowledge for practitioners and academia.

Furthermore, researches in marketing and consumer behavior agree that inertia is a facilitator of behavioral loyalty [13]. It's been described as a condition where customers' repeat purchases occur because of their laziness, inactiveness, or passiveness [13]. A strong inertia customers perceived means their disinterest in actively processing relevant information to make the best possible choice[13, 14]. Thus, inertia leads them to repeat the same purchase pattern, similar to a habit [15], concentrating on familiar few organic/non-organic foods. However, fewer studies have been done to the buying behavioral of organic food. Thus, examination of the role of inertia in intention formation contributes to the existing organic foods literature.

Therefore, this study examines the role of a psychological motive (i.e., self-congruity) and inertia that have been identified in previous organic food studies or marketing literature. The current research demonstrates the relative importance of this variable in stimulating consumers' consumption of organic foods. To our knowledge, this study is likely to be the first study to clarify the importance of self-congruity in predicting consumers' intention to purchase organic foods. Therefore, the results enrich our understanding of key drivers of consumers' organic food purchase.

\section{Hypothesis development}

\subsection{The concept of self-congruity}

The concept of self-congruity comes from self-concept or self-image. Self-congruity is referred to a matching process which a shopper/buyer make a decision to patronize a store, he/she is likely to compare the store patron image with his/her own self-concept [16]. Another also stated the congruity of self-concept with product or brand mental representation refers to the match between those two images (i.e. products/service and his/her own) and plays an important role in consumer behavior since it constitutes a basic mechanism on which individuals base their brand preferences [17]. Research has demonstrated that the need for individual reassurance from others is one of the basic principles of selfconcept that drive consumers [18]. This means that the consumers towards a product/service were likely to driven because their needs for reassurance. They symbolically relate their belongings in such a way that, on analysis, some significance can be read into their aspirations to success, social acceptance, ostentation, or prestige through the self-concept/product image congruity mechanism [17].

The self-congruity hypothesis is rooted in the assumption that individuals strive to maintain cognitive consistency in their beliefs and behaviors. Thus, consumers prefer those products or brands whose image is congruent with their own self-image [18]. Empirical study have evidenced that a higher level of self-congruity is experienced when a shopper perceives a greater match between the typical mall shopper image and his/her own self-image [16]. And this higher level of self-congruity can lead to a higher level of behavioral intention. Likewise, the stronger the congruence between the perceived personality of the brand and the consumer's own personality, the more likely the consumer is to buy this brand [19]. This implies that an organic food/product- self congruity is likely to enhance consumer's behavioral intention. Hence, building on these theoretical arguments and empirical findings, a hypothesis is proposed as follows:

H1: Self-congruity consumer perceived has positive influence on behavioral intention toward organic food.

Self-congruity was proved to be an antecedent of customer attitude toward products and a predictor of their shopping behavior [20, 21, 22, 23]. According to functional attitude theory, one of 
the important motives for customers in their purchase behavior is to solidify and express those values which are important to them [24-25]. When customers identify that the store image is congruent with their self-image, they agree that the store can represent their identity, and thus, favorable attitudes will be formed [18]. This implies that after the consumers identify the organic food image is congruent with their self-image; the level of their attitudes is likely to be higher. Based on the discussion above, a hypothesis is proposed as follows:

H2: Self-congruity consumer perceived has positive influence on attitudes toward organic food.

\subsection{The concept of attitudes}

Attitude is “a person's consistently favorable or unfavorable evaluation, feelings, and tendencies toward an object or idea"[26]. It can also be described as "the degree to which a person has a favorable or unfavorable evaluation or appraisal of the behavior in question" [27]. Attitudes toward a behavior is believed to be a function of one's salient beliefs (i.e., behavioral beliefs (BB)), which represent the perceived consequences of the behavior and his/her evaluation of the significance of the consequences (i.e., outcome evaluation (OE)) [28]. It includes judgment on whether the behavior under consideration is good or bad, and whether the actor wants to do the behavior [29].

Research has also demonstrated it is a function of behavioural beliefs; if an individual believes the performance of a specific behaviour will lead to a positive outcome then he/she will develop a favourable attitude towards that behaviour [30]. It influence the intentions held and the more favourable the attitude, the greater the intention to perform the behaviour will be. When determining whether to perform a specific behavior, a person is likely to assess the benefits and the costs resulting from the behavior [31]. For example, in our case, consumers could perceive eating organic foods as experiencing a healthy environmentally friendly activities, eating fresh and healthy food, and being more socially responsible, etc.

Additionally, attitudes are predictors of purchase intentions and consequently purchase behaviour [27]. Research has demonstrated that an individual tends to possess a favorable attitude when the outcomes are positively evaluated and, thus, he/she is likely to engage in that specific behavior [27, 31, $32,33]$. In other words, an individual's positive attitude toward a certain behavior strengthens his/her intention to perform the behavior [27]. In our case, consumers who possess favorable attitudes towards organic foods are likely to engage in that specific behavior in terms of the positive intentions of words of mouth, recommend to others, and purchase behaviour.

Attitudes are the main important predictor of behavioral intention and are the psychological emotion routed through consumers' evaluations and, if positive, BI tend to be more positive [34]. More specifically, in the context of green products, a positive relationship between attitude and behavioral intention has been established across many cultures [35]. Based on the discussion above, a hypothesis is proposed as follows:

H3: Attitudes consumer perceived have positive influence on behavioral intention toward organic food.

\subsection{The effects of inertia on variables' relationships}

Inertia is perceived as customers not switching because it is 'too much bother in terms of time and effort' [36]. Yanamandram \& White (2006) described inertia as a condition where customers' repeat purchases occur because of their laziness, inactiveness, or passiveness. In other words, such customers' repeat purchases result simply from a lack of goal-directed behaviors [37], from a lack of conscious decision to change [38], or from being conditioned by habit [15].

In this situation, the customer repeats the same buying behaviour to limit the information search process and the cost of thinking [39]. The repeat purchase may even be in spite of the customer reflects a non-conscious process [38]. Repeat purchase as a result of inertia is unstable, reflecting little or no brand commitment [40] and merely represents acceptance [41]. Thus, high-inertia customers are passive in contemplating switching, thereby resulting in them remaining status quo with their service 
providers. Low-inertia customers may be actively searching for and comparing deals, consequently leading to their defections $[36,37]$. Therefore, inertia is likely to play a moderated role in decisionmaking process. Hence, the hypotheses are proposed as follows:

H4a: Inertia significantly moderates the self-congruity-attitudes relationship.

H4b: Inertia significantly moderates the self-congruity-behavioral intention relationship.

H4c: Inertia significantly moderates the attitudes-behavioral intention relationship.

\section{Methodology}

\subsection{Questionnaire design}

Having considered the data collection requirements of this study such as a need of large sample of organic food consumers in Fujian province, it would be appropriate to employ the field survey with a self- administered questionnaire as the primary data collection technique. The population was set on those organic food consumers who consume organic food during the past six month. Organic firms were conducted for collecting data. After giving them phone call/interview by the researcher, finally four organic firms agreed to give us help in collecting data. They were found more than 5 years, stood on a standard of operation, and could be the representation of organic food firms in Fujian province. Their main products of those firms were fresh organic vegetables, organic tea, and others.

The field study method was chosen in order to gain information directly from organic food consumers who consume organic food during the past six month. As such, their perceptions about the setting with respect to self-congruity (SC), attitude(AT), and behavioral intention (BI) are likely to be clearly in mind. The survey instruments were borrowed from previous studies and adapted for this study. Self congruity was defined as how a consumer hopes others see her/him. A consumer's self congruity comprises their actual self-congruity, ideal self-congruity, social self-congruity, and ideal social self-congruity [18]. Four items for self congruity are distinguished, based on the studies of Ryu \& Lee (2013) [42] and Yen (2014) [43]. Attitudes toward to organic foods were defined as a consumer's evaluation of the significance of the consequences/outcomes[27]. The three items adopted for attitude are based on the studies of Ajzen (1991) [27]and Kang et al. (2012) [21]. Behavioral intention was defined as a consumer's evaluation of the intents to word-of-mouth, recommendation, and repurchase[44].Three items for behavioral intentions are drawn from Lee \& Yun (2015) [44]and Yen (2013) [45].

\subsection{Sampling and Respondent profile}

Quota sampling was adopted for collecting data based upon firms' scale. Regarding to the feasibility and accessibility, four firms were adopted for collecting data after conducting to legal organic firms in Fujian province. They have offered the member list for sending questionnaires or space for surveyors to interview the organic food consumers. Survey was down during May to June in 2016. Finally a total of 305 samples were received. After non-qualified and incomplete surveys were excluded, the remaining 295 respondents were valid reporting a responds rate of valid samples was $96.7 \%$.

\subsection{Respondent profile}

Of 295 questionnaires obtained, about $40.7 \%$ were male and $55.3 \%$ were from female respondents. At about $40.3 \%$ of respondents were $20-29$ years of age, $23.7 \%$ of respondents were $30-39$ years of age, $16.6 \%$ of respondents were $40-49$ years of age, $8.1 \%$ of respondents were $50-59$ years of age, and $3.1 \%$ exceed 60 years of age. Regarding to married status, $51.2 \%$ of respondents was single, $11.5 \%$ of respondents were married with no children while $31.5 \%$ of respondents were married with children. Approximately $3.8 \%$ of respondents were graduated from senior high school, $10.2 \%$ of respondents received a bachelor degree and the majority of respondents got a master degree $(61.4 \%)$. With regard 
to the occupation, $14.2 \%$ of respondents work at government related sectors, $5.1 \%$ of respondents belong to industrial sector, $37.3 \%$ of respondents were businessman, $13.2 \%$ of respondents were farmers, $22 \%$ of respondents were students, and $5.4 \%$ of respondents were retired/else. Approximately $42.4 \%$ of respondent's monthly income was below 3000RMB, $32.9 \%$ of respondent's monthly income was 3001-6000 RMB, and 13.2\% of respondent's monthly income was 6001-8000 RMB while 5.1\% of respondent's monthly income exceeds $8000 \mathrm{RMB}$. With regard to the frequency consumed within six month, $45.8 \%$ of respondents were less than three times, $28.8 \%$ of respondents were $4-6$ times, and $21 \%$ of respondents were more than seven times. Table 1 reports the demographic characteristic.

Table 1. Demographic statistics $(n=295)$

\begin{tabular}{|c|c|c|c|c|c|c|c|}
\hline \multicolumn{2}{|r|}{ Items } & \multirow{2}{*}{$\frac{\text { Freq. }}{120}$} & \multirow{2}{*}{$\frac{\%}{40.7}$} & \multicolumn{2}{|r|}{ Items } & \multirow{2}{*}{$\frac{\text { Freq. }}{42}$} & \multirow{2}{*}{$\frac{\%}{14.2}$} \\
\hline Gender & Male & & & \multirow{8}{*}{ Occupation } & Public sector & & \\
\hline 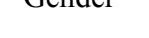 & Female & 163 & 55.3 & & Industrial sector & 15 & 5.1 \\
\hline & NA & 12 & 4.1 & & Business & 110 & 37.3 \\
\hline & $20-29$ & 119 & 40.3 & & Agriculture & 39 & 13.2 \\
\hline \multirow{4}{*}{ Age } & $30-39$ & 70 & 23.7 & & Student & 65 & 22.0 \\
\hline & $40-49$ & 49 & 16.6 & & Retired (else) & 16 & 5.4 \\
\hline & $50-59$ & 24 & 8.1 & & NA & 8 & 2.7 \\
\hline & $>60$ & 9 & 3.1 & & & & \\
\hline \multirow{6}{*}{$\begin{array}{l}\text { Married } \\
\text { Status }\end{array}$} & NA & 24 & 8.1 & \multirow{6}{*}{$\begin{array}{l}\text { Monthly } \\
\text { Income }\end{array}$} & $<3000$ & 125 & 42.4 \\
\hline & Single & 151 & 51.2 & & $3001-6000$ & 97 & 32.9 \\
\hline & $\begin{array}{l}\text { Married with No } \\
\text { Children }\end{array}$ & 34 & 11.5 & & $6001-8000$ & 39 & 13.2 \\
\hline & $\begin{array}{l}\text { Married with } \\
\text { Children }\end{array}$ & 93 & 31.5 & & $>8001$ & 15 & 5.1 \\
\hline & Separate & 7 & 2.3 & & NA & 19 & 6.4 \\
\hline & NA & 10 & 3.4 & & & & \\
\hline \multirow{6}{*}{ Education } & Primary & 2 & .7 & \multirow{6}{*}{$\begin{array}{c}\text { Frequency } \\
\text { consumed } \\
\text { within six } \\
\text { month }\end{array}$} & $<3$ & 135 & 45.8 \\
\hline & High & 9 & 3.1 & & $4-6$ & 85 & 28.8 \\
\hline & College & 30 & 10.2 & & $>7$ & 62 & 21.0 \\
\hline & Bachelor & 52 & 17.6 & & NA & 13 & 4.4 \\
\hline & Master & 181 & 61.4 & & & & \\
\hline & NA & 21 & 7.2 & & & & \\
\hline
\end{tabular}

NA: not available

\section{Result}

\subsection{Common method variance assessment}

The potential occurrence of common method variance (CMV) was tested by employing a Harman's one-factor test. An exploratory factor analysis containing all seven reflective indicators was conducted. Consistent with the measurement model, the results of the principal components factor analysis reveal that there are three factors that account for $73 \%$ of the total variance. CMV does not appear to be a problem, since the first factor did not account for the majority of the variance (only $23.5 \%$ ). Moreover, a CFA approach to Harman's one-factor test was used to assess whether a single latent factor accounts for all manifest variables. The one-factor model yielded a $\chi^{2}$ of $4207.81(\mathrm{df}=702)$ compared with a $\chi^{2}$ of $1322.80(\mathrm{df}=647)$ for the three-factor measurement model in which manifest variables were assigned to load onto their theoretical constructs. The fit is considerably worse for the unidimensional model than for the measurement model $\left(\Delta \chi^{2}=1885.01, \Delta \mathrm{df}=55, \mathrm{pb} .01\right)$ suggesting that $\mathrm{CMV}$ is not a serious threat in the study. Finally, the major focus of this study is on interaction effects; however, CMV usually works against differential validity. 


\subsection{Measure assessment for formative scales}

A confirmatory factor analysis using AMOS 17.0 is conducted to test the measurement model. Table 2 reports the results. The chi-squares $(82.43)$ are significant $(\mathrm{p}<0.05 ;$ [46]). The ratios of chi-square to degrees of freedom $(\mathrm{df}=31)$ are 2.65 for measurement model within the acceptable range of 2 to 5 [47]. The values for GFI (0.949), AGFI (0.909), CFI (0.975), and RMSEA (0.075) are acceptably close to the standards suggested by $\mathrm{Hu} \&$ Bentler (1999) [48] greater than 0.9 for GFI and AGFI, greater than 0.95 for CFI and less than 0.08 for RMSEA. Given that these batteries of overall goodness-of-fit (GFI) indices were accurate and that the model was developed on theoretical bases, and given the high level of consistency samples, no respecifications of the model were made. This enables authors to proceed in evaluating the reliability and validity.

Table 2. Reliability and validity

\begin{tabular}{ccccccc}
\hline Conpt. & Items & $\lambda$ & t-values & SMC & CR & AVE \\
\hline SC & SC1 & .755 & - & .570 & 0.791 & 0.486 \\
& SC2 & .839 & 14.785 & .704 & & \\
& SC3 & .888 & 15.675 & .789 & & \\
& SC4 & .826 & 14.537 & .683 & & \\
AT & AT1 & .754 & - & .568 & & \\
& AT2 & .899 & 15.683 & .808 & & \\
& AT3 & .847 & 14.864 & .718 & & \\
BI & BI1 & .871 & - & .759 & 0.864 & \\
& BI2 & .907 & 20.663 & .822 & & \\
& BI3 & .737 & 15.070 & .543 & & \\
\hline
\end{tabular}

SC: Self congruity; BI: Behavioral intention; $\lambda$ : Standardized factor loading; CR: Composite reliability; AVE: Average variance extracted; $\chi^{2}=82.43, \mathrm{df}=31(\mathrm{p}=.000), \chi^{2} / \mathrm{df}=2.65, \mathrm{GFI}=.949$, AGFI=.909, CFI=.975 , RMSEA $=.075$

Assessment of a formative index requires the examination of five critical aspects: (1) content specification, (2) indicator specification, (3) indicator collinearity, (4) individual indicator validity, and (5) construct validity. The definition stems from a detailed and systematic literature review supplemented with field-based interviews, a process that resulted in the generation of four indicators specifying the one dimension comprising the index. The domain of the dimension has been captured because all the items characterizing each dimension have been included in the corresponding index. Similarly, an inclusive set of items capturing the domains of one dimension was generated. Consequently, the definition and measurement of the index capture the breadth of the conceptual domain, thereby satisfying the content and indicator specification criteria.

To assess collinearity, we regressed indicators on the sum score of the self congruity index; the highest variance inflation factor (VIF) was 3.55, which is considerably below the threshold of 10 , and thus, multicollinearity is not an issue. Individual indicator validity assessment was conducted by fitting a multiple indicators and multiple causes (MIMIC) model. The MIMIC model was identified by specifying two structural relations from the formative index to two reflectively measured constructs (attitudes and behavior intention). The results of the MIMIC model indicate that the overall model has a very good fit $(\chi 2=93.04, \mathrm{df}=69, \mathrm{p}$-value $=.028 ; \mathrm{SRMR}=.050 ; \mathrm{RMSEA}=.045 ; \mathrm{CFI}=.98$; $\mathrm{NNFI}=.98$; and $\mathrm{GFI}=.93)$ and all four $\gamma$-parameters exerted a significant effect on sales strategy.

Construct validity was assessed in three ways. First, the CFA model and the regression analyses (to be discussed subsequently) show that self congruity is significantly related to attitude and behavioral intention measures. Second, the error variance of the self congruity construct as estimated in the CFA model is .24, which indicates that it is a valid construct. Finally, we calculated the inter correlations among the self congruity as well as the Cronbach's alpha reliability coefficient for the construct. Again, the results speak against the possibility of a reflective structure for the self congruity measure because the inter correlations ranged from .06 ( $\mathrm{pN} .10)$ to .32 (pb.01) with an average value of .17, whereas the reliability coefficient was .896 . 


\subsection{Measure assessment for reflective scales}

This study evaluated reflective scales by means of one covariance-based CFA. The CFA was run on attitude and behavioral intention. The overall fit of the first measurement model was good: root mean square error of approximation $(\mathrm{RMSEA})=.075$; comparative fit index $(\mathrm{CFI})=.975$; goodness-of-fit index $(\mathrm{GFI})=.949$; and adjusted goodness-of-fit index $(\mathrm{AGFI})=.909$. In addition, all indicators loaded significantly on their hypothesized latent construct, which demonstrates convergent validity. Table 2 reveals that the average variance extracted (AVE) for each of the measures is greater than the shared variance between any pair of measures, thereby satisfying the criterion of discriminant validity [49]. Finally, the constructs' composite reliabilities (CRs) indicate that each exceeded the accepted reliability threshold of .70.

\subsection{Hypotheses testing}

The overall model fit indices show that the chi-squares $(82.43)$ are significant $(p<0.05)$; the ratios of chi-square to degrees of freedom $(\mathrm{df}=31)$ are 2.65 for structural model within the acceptable range of 2 to 5; the values for GFI (0.949), AGFI (0.909), CFI (0.975), and RMSEA (0.075) are acceptably close to the standards suggested by $\mathrm{Hu} \&$ Bentler (1999) greater than 0.9 for GFI and AGFI, greater than 0.95 for CFI and less than 0.08 for RMSEA. This suggests that the hypothesized model fits the empirical data well. Table 3 shows the estimated model with the standardized path coefficients. SC can directly and significantly impact AT $(t=9.069, \beta=0.635)$. Thus H1 was supported. Moreover, SC can also directly and significantly impact $\mathrm{BI}(\mathrm{t}=3.828, \beta=0.225)$. Thus $\mathrm{H} 2$ was supported. Finally $\mathrm{BI}$ can be influenced by AT ( $\mathrm{t}=9.869, \beta=0.703)$. Thus H3 was supported. The $\mathrm{R}^{2}$ is for AT .404 and .745 for BI. Table 3 reports the results of structural model.

Table 3. Results of SEM

\begin{tabular}{cccc}
\hline Path and items & $\beta$ & $\mathrm{t}$ & SMC \\
\hline SC-AT & .635 & 9.069 & .404 \\
SC-BI & .225 & 3.828 & .745 \\
AT-BI & .703 & 9.869 & \\
\hline$\chi^{2}=82.43, \mathrm{df}=31(\mathrm{p}=.000), \chi^{2} / \mathrm{df}=2.65, \mathrm{GFI}=.949$, AGFI $=.909, \mathrm{CFI}=.975, \mathrm{RMSEA}=.075$ &
\end{tabular}

\subsection{The moderated effects of inertia}

The mean-centered of relevant variables were done before creating the interaction terms. Then two interactional variables were added into the estimated model. Table 4 reports the results of moderated effects. Again, the overall model fit indices show that the chi-squares $(98.27)$ are significant $(\mathrm{p}<0.05)$; the ratios of chi-square to degrees of freedom $(\mathrm{df}=46)$ are 2.136 within the acceptable range of 2 to 5 ; the values for GFI (0.949), AGFI (0.914), CFI (0.977), and RMSEA (0.062) are acceptably close to the standards suggested by Hu \& Bentler (1999) greater than 0.9 for GFI and AGFI, greater than 0.95 for CFI and less than 0.08 for RMSEA. This suggests that the hypothesized model fits the empirical data well. The results show that $\mathrm{SC}$ can directly and significantly impact $\mathrm{AT}(\mathrm{t}=8.625, \beta=0.612)$. Thus H1 was supported. Moreover, SC can also directly and significantly impact $\mathrm{BI}(\mathrm{t}=3.875, \beta=0.231)$. Thus H2 was supported. Finally BI can be influenced by AT $(\mathrm{t}=9.884, \beta=0.705)$. Thus H3 was supported. The $\mathrm{R}^{2}$ is for AT .411 and .751 for BI. Moreover, the moderator, inertia has moderated effects on SC-BI $(\mathrm{t}=1.974, \beta=0.104)$ and AT-BI $(\mathrm{t}=-1.816, \beta=-0.096)$ relationships. Thus H5 and H6 were supported while $\mathrm{H} 4$ was not supported.

Table 4. Results of Moderated Effects

\begin{tabular}{cccc}
\hline Path and items & $\beta$ & $\mathrm{t}$ & SMC \\
\hline SC-AT & .612 & 8.625 & .411 \\
SC-BI & .231 & 3.875 & .751 \\
AT-BI & .705 & 9.884 &
\end{tabular}




\begin{tabular}{rcc} 
INT*SC-AT & -.080 & -1.494 \\
INT*SC-BI & .107 & 1.974 \\
INT*AT-BI & -.096 & -1.816 \\
\hline
\end{tabular}

$\chi^{2}=98.27, \mathrm{df}=46(\mathrm{p}=.000), \chi^{2} / \mathrm{df}=2.136, \mathrm{GFI}=.949, \mathrm{AGFI}=.914, \mathrm{CFI}=.977, \mathrm{RMSEA}=.062$

\section{Conclusion and Suggestion}

The present study tested a model to determine whether behavioral intention is predicted by selfcongruity and attitudes, and how the predictive relationships are moderated by inertia. The results found: (1) behavioral intention was predicted by self-congruity and attitudes; (2) however, the predictive power of attitudes was stronger and more direct than self-congruity; (3) attitudes toward organic food were predicted by self-congruity; (4) the high inertia group exhibited stronger associations between self-congruity and behavioral intention than the low one; and (5) the high inertia group exhibited weaker associations between attitudes and behavioral intention than the low one. Implications are suggested based on these findings.

As previous studies explained, the simultaneous of self-congruity have been understood, while its effects have not been examined in the theoretical context of inertia. Thus, the results indicate several theoretical contributions.

First, social self- congruity was found to be the most important one in influencing attitudes and behavioral intention, and followed by ideal self- congruity, ideal social self- congruity, and actual selfcongruity when purchasing organic food. This finding was different from previous studies. In the selfcongruity literature, whether actual- and ideal self- congruities are similar or dissimilar are conflicting. Given these divergent findings, it's reasonable to speculate that the conflicting results are partially due to the range of products investigated [50]. Specifically, it might be that actual self- congruity and social self- congruity are not the case in organic food contexts because such purchases do not fall into the category of mundane and routine occurrences. This pattern is quite different from other food purchases due to its high price and special meanings for health benefits and environmental concerns.

Furthermore, the finding that the predictive power of attitudes was stronger and more direct than self-congruity contributes to the attitudes literature. Since self-congruity represents the valueexpressive function, this finding suggests that organic foods are dissimilar to conventional foods. Their attitudes toward organic foods are likely to determine by multiple ways in terms of the level of monthly income, educational background etc. Specifically, attitudes toward organic foods are also a mediator between self-congruity and behavioral intention. This implies it is a key factor when forming behavioral intention to consumers in organic food contexts. Therefore, both self-congruity and attitudes are appropriate theories for identifying dominant of organic foods.

Moreover, the finding that attitudes toward organic food were predicted by self-congruity implies self-congruity can be one of the antecedents of attitudes. In line with previous studies, Attitude is "a person's consistently favorable or unfavorable evaluation, feelings, and tendencies toward an object or idea"[26]. These evaluation, feelings, and tendencies should comprise the comparison of products image and consumers' self-image. The attitudes are likely to be favorable while the evaluation toward the products can match his/her self-image. Therefore, these self-congruities are likely to enhance his/her attitudes toward

Specifically, the finding that the high inertia group exhibited stronger associations between selfcongruity and behavioral intention than the low one; and the high inertia group exhibited weaker associations between attitudes and behavioral intention than the low one contributes to the existed inertia literature. That is previous studies state that high levels of inertia weaken the association between post purchase decision/behavior and its predictors [33]. However this study suggests that both positive and negative effects of inertia on variables can be met. Such individual-level factors as inertia moderates the influence of self-congruity and behavioral intention. In particular, individuals' self-congruity has greater effects on behavioral intention at high values of inertia than at low values of inertia. This means that as the comparisons of products image and his/her image are congruence, the high intents to word-of-mouth, recommendation, and repurchase are met. Because high-inertia 
customers are passive in contemplating switching, thereby resulting in them remaining status quo with their service providers.

In contrast, individuals' attitudes have greater effects on behavioral intention at low values of inertia than at high values of inertia. It indicates such contingency variable will destroy the attitudesintention relationship. Because low-inertia customers may be actively searching for and comparing deals, consequently leading to their defections, the effects of attitudes on behavioral intention are thus decline.

\section{References}

1. J. van Doorn and P.C. Verhoef, Journal of Retailing, 91(3), 436-450 (2015)

2. L. Marian, P. Chrysochou, A. Krystallis and J. Thogersen, Food Quality and Preference, 37, 5260 (2014)

3. N. Michaelidou and L.M. Hassan, International Journal of Consumer Studies, 32(2), 163-170 (2008)

4. A. Milman and A. Pizam, Annals of tourism research, 15(2), 191-204 (1988)

5. M. Wandel and A. Bugge, Food Quality and Preference, 8(1), 19-26 (1997)

6. S. Baker, Thompson, K.J. Engelken and K. Huntley, European journal of marketing, 38(8), 9951025 (2004)

7. J. Hwang, Journal of Retailing and Consumer Services, 28, 281-287 (2016)

8. J.L. Aaker, Journal of marketing research, 34, 347-356 (1997)

9. F. Kressmann, M. Sirgy, A. Herrmann, F. Huber, S. Huber and D.D. Lee, Journal of Business Research, 59(9), 955-964 (2006)

10. P.H. Chiu, T.F. Yen and K.K. Chu, Journal of Food, Agriculture \& Environment, 13(3), 168-174 (2015)

11. T. Graeff, Journal of consumer marketing, 13(3), 4-18 (1996)

12. T. Ramayah, J. Lee and O. Mohamad, Green product purchase intention: some insights from a developing country. Resources, Conservation and Recycling, 54(12), 1419-1427 (2010)

13. M. Kotchen and S. Reiling, Ecological Economics, 32(1), 93-107 (2000)

14. V. Yanamandram and L. White, International Journal of Service Industry Management, 17(2), 158-192 (2006)

15. W. Kim, C. Ok and D.D. Canter, International Journal of Hospitality Management, 29(1), 136$147(2010)$

16. C. Bozzo, Journal of Customer Behaviour, 1(3), 335-355 (2002)

17. K.El. Hedhli, H. Zourrig and J.C. Chebat, Journal of Retailing and Consumer Services, 31, 1-13 (2016)

18. A. Beerli, G.D. Meneses and S.M. Gil, Annals of Tourism Research, 34(3), 571-587 (2007)

19. M.J. Sirgy, Journal of consumer research, 9, 287-300 (1982)

20. A.Usakli and S. Baloglu, Tourism management, 32, 114-127 (2011)

21. D. Lee and M.R. Hyman,. Journal of Marketing Theory and Practice, 16 (3), 219-232 (2008)

22. J. Kang, L. Tang, J.Y. Lee and R.H. Bosselman, International Journal of Hospitality Management, 31(3), 809-818 (2012)

23. T.F. Yen, The effects of gender on self congruity- behavioral intention relationships: An empirical study of organic food consumers in Fujian province, China. J. Lei., Tou., Spo., \& Hea. 7, $\mathrm{x}-\mathrm{xx}(2017$, in press)

24. M.J. Sirgy and A. Samli, Journal of the Academy of Marketing Science, 13(3), 265-291 (1985)

25. M.J. Sirgy, D. Grewal and T.F. Mangleburg, Journal of Business research, 49, 127-138 (2000)

26. H.H. Chang and Y.M. Liu, The Service Industries Journal, 29(12), 1687-1706 (2009)

27. I. Ajzen, Organizational Behavior and Human Decision Processes, 50(2), 179-211 (1991)

28. A.H. Eagry and S. Chailen, Psychology of attitudes. Fort Worth, TX: Harcourt Brace Jovanovich. (1993)

29. M. Leonard, S. Graham and D. Bonacum, Quality and Safety in Health Care, 13, 85-90 (2004) 
30. I. Ajzen and M. Fishbein, Understanding attitude and predicting social behavior, Englewood Cliffs, NJ: Prentice-Hall, Inc (1980)

31. S. Cheng, T. Lam and C.H.C. Hsu, International Journal of Hospitality Management, 24(4), 475492 (2005)

32. M.J. Lee, Effects of attitude and destination image on association members' meeting participation intentions: development of meeting participation model. Unpublished doctoral dissertation, Manhattan, KS: Kansas State University. (2005)

33. H. Han, Y. Kim and E. Kim, International Journal of Hospitality Management, 30(2), 1008-1019 (2011)

34. M.F. Chen and P.J. Tung, International journal of hospitality management, 36, 221-230 (2014)

35. M.M. Mostafa, Psychological Marketing, 24(5), 445-473 (2007)

36. M. Colgate, B. Lang, Journal of consumer marketing, 18(4), 332-347 (2001)

37. M. Zeelenberg and R. Pieters, Journal of business Research, 57(4), 445-455 (2004)

38. M. Huang and S. Yu, Psychology and Marketing, 16(6), 523-544 (1999)

39. K. Bawa, Marketing Science, 9(3), 263-278 (1990)

40. M.R. Solomon, G. Bamossy and S. Askegaard, Consumer behaviour: A European Perspective, 2nd edition, Pearson Education, Harlow (2002)

41. H. Assael, Consumer behaviour and marketing action, Southwestern College. Publishing, Cincinnati, OH (1998)

42. K. Ryu and J.S. Lee, International Journal of Hospitality Management, 33, 29-40 (2013)

43. T.F. Yen, J. Spo. Lei. Hos. Res. 9(1), 27-55 (2014)

44. H.J. Lee, Z.S. Yun, Food Quality and Preference, 39, 259-267 (2015)

45. T.F. Yen, Leisure Industry Research, 11(3), 1-10 (2013)

46. K.A. Bollen, Structural Equations with Latent Variables, New York, John Wiley and Sons. (1989)

47. H.W. Marsh and D. Hovecar, Psychological Bulletin, 97(3), 562-582 (1985)

48. L. Hu and P.M. Bentler, Structural Equation Modeling: A Multidisciplinary Journal, 6(1), 1-55 (2009)

49. C. Fornell and D.F. Larcker, Journal of marketing research, 18, 382-388 (1981)

50. H. Choi, L.N. Reid, Journal of Business Research, 69(9), 3430-3438 (2016) 